\title{
Correction to: Characterization and potential application of gleysols and ferralsols for ceramic industry: a case study from Dimako (Eastern Cameroon)
}

Josti M. Doum ${ }^{1} \cdot$ Gentry C. Fuh ${ }^{1}$. Soureiyatou Fadil-Djenabou ${ }^{2} \cdot$ Vincent Laurent Onana $^{1} \cdot$ Paul-Désiré Ndjigui $^{1}$. John S. Armstrong-Altrin ${ }^{3}$

Published online: 31 October 2020

(C) Saudi Society for Geosciences 2020

Correction to: Arabian Journal of Geosciences (2020) 13:1074

https://doi.org/10.1007/s12517-020-06007-0

The original version of this paper was published with error. Figure captions were incorrectly assigned to its corresponding images. Given in this article are the correct figures and captions.

The original article has been corrected.

The online version of the original article can be found at https://doi.org/ 10.1007/s12517-020-06007-0

Paul-Désiré Ndjigui

lndjigui@yahoo.fr

1 Department of Earth Sciences, University of Yaoundé I,

P.O. Box 812, Yaoundé, Cameroon

2 Department of Life and Earth Sciences, Higher Teachers' Training College, University of Maroua, P.O. Box 55, Maroua, Cameroon

3 Instituto de Ciencias del Mar y Limnología, Unidad de Procesos Oceánicos y Costeros, Ciudad Universitaria, Universidad Nacional Autónoma de México, 04510 Ciudad de México, Mexico 


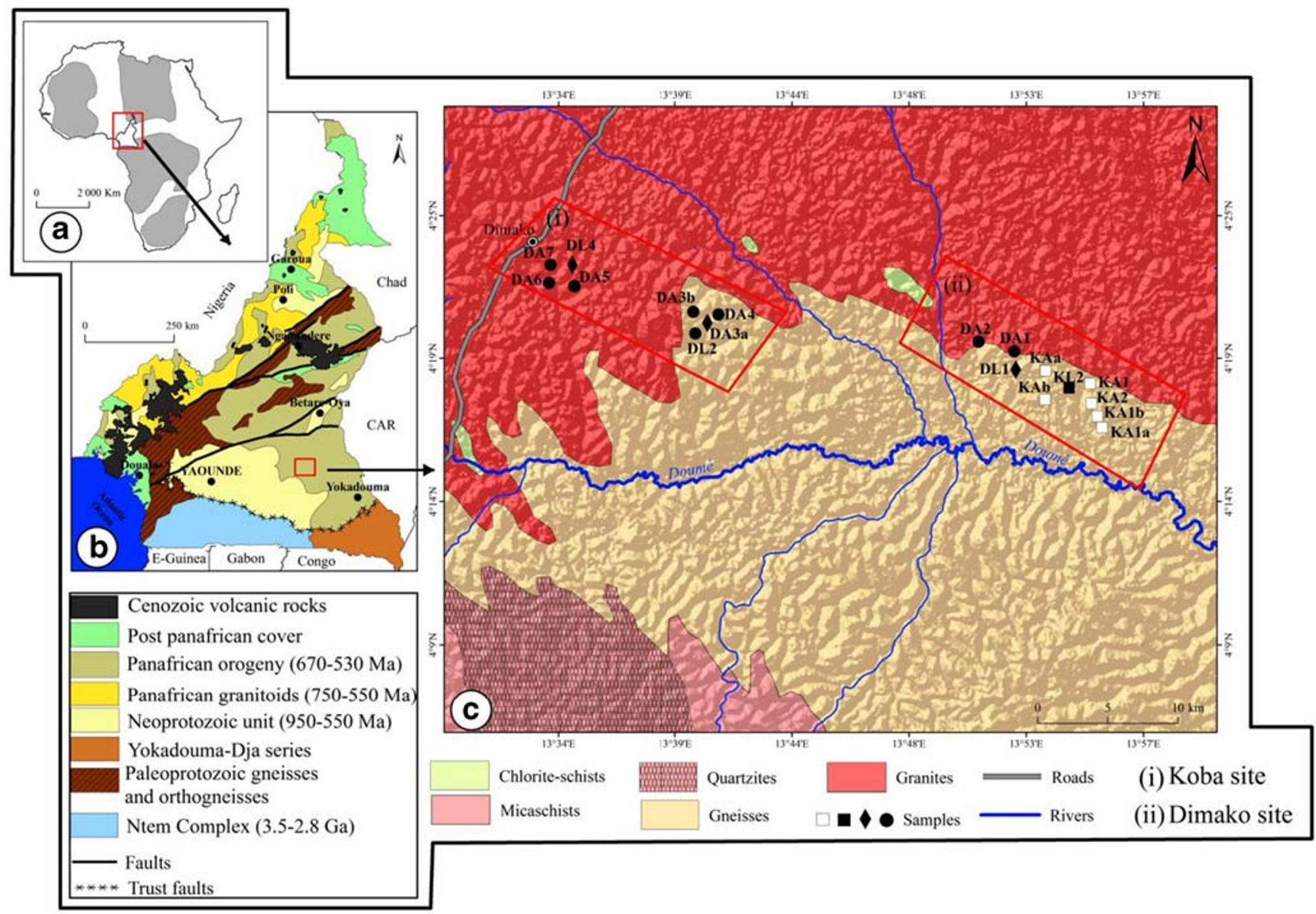

Fig. 1 a) Location of Cameroon relative to African cratons. b) Geological map of Cameroon locating the study area (Toteu et al. 2001). c) Geological map of Dimako showing sampling location (Asaah et al. 2015)

Fig. 2 Typical profiles of

gleysols (a) and ferralsols (b) at Dimako
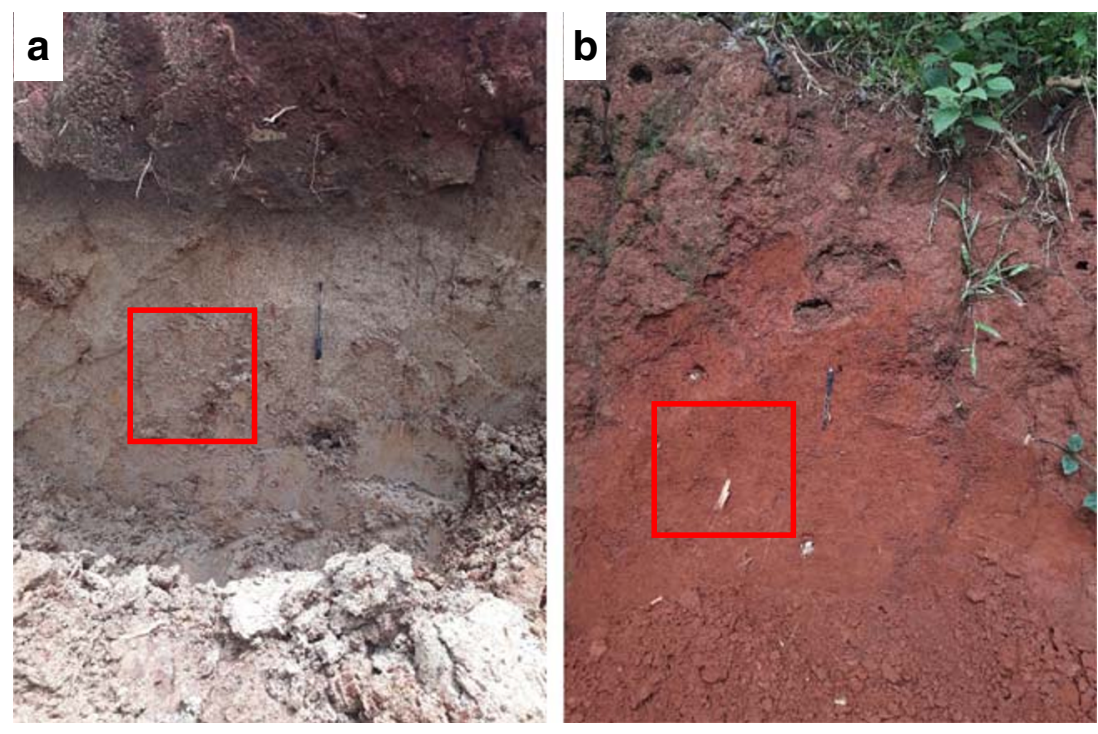
Fig. 3 Characterization of soil texture from Dimako using the ternary diagram

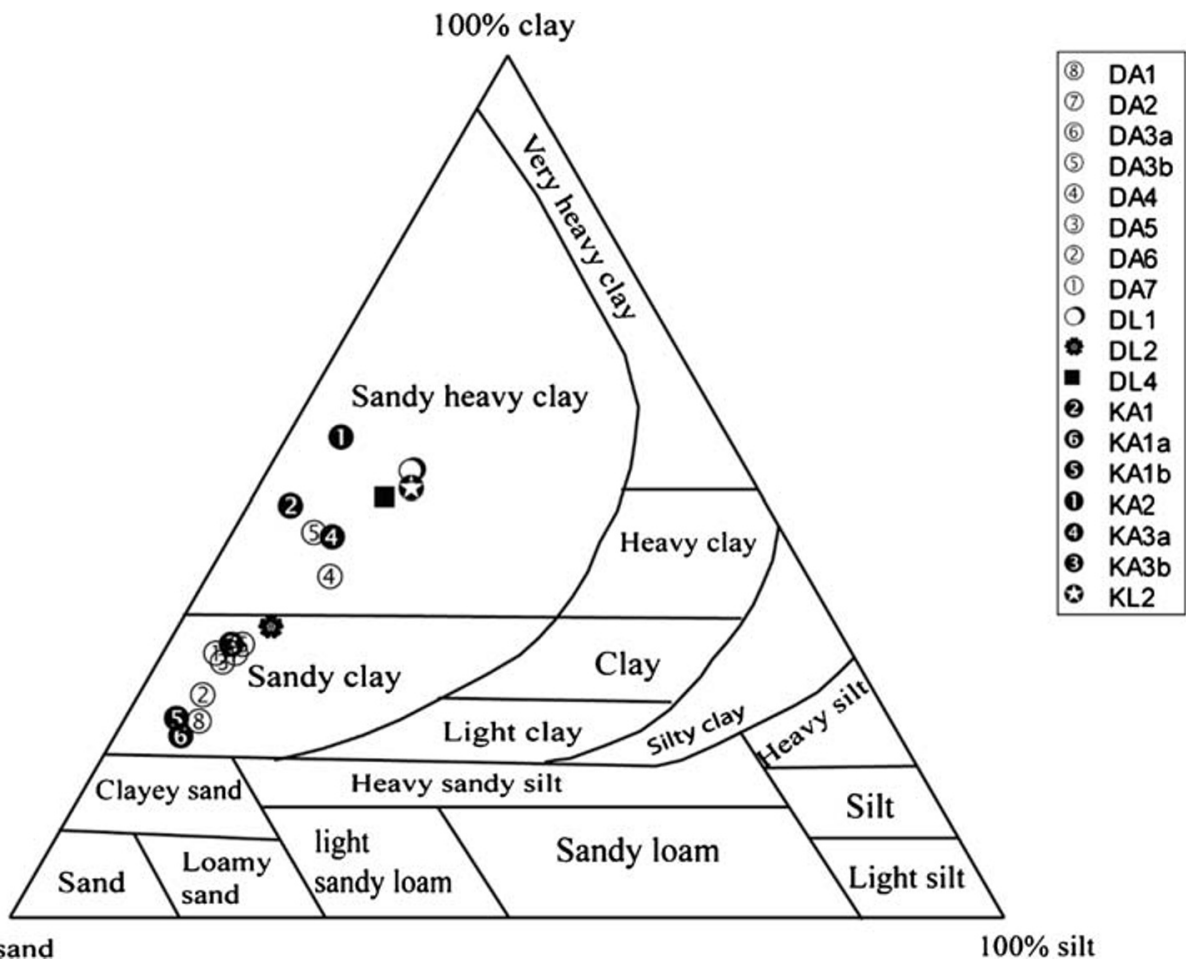

(a)
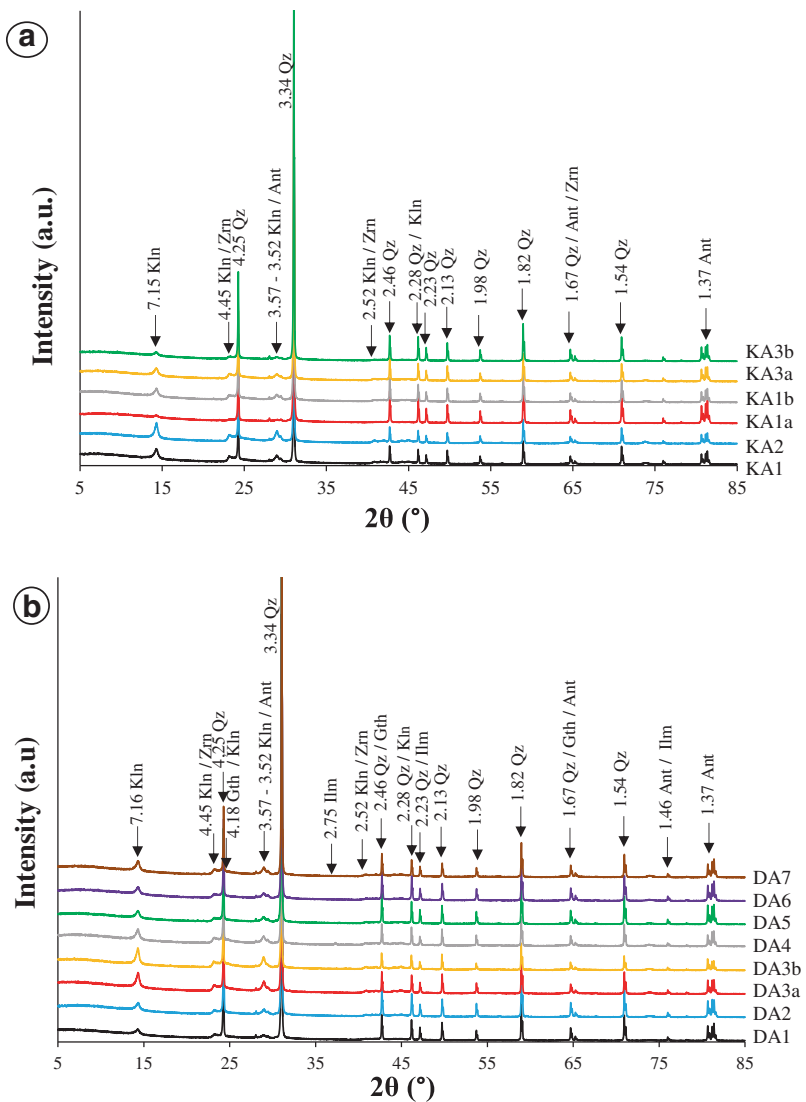

(C)

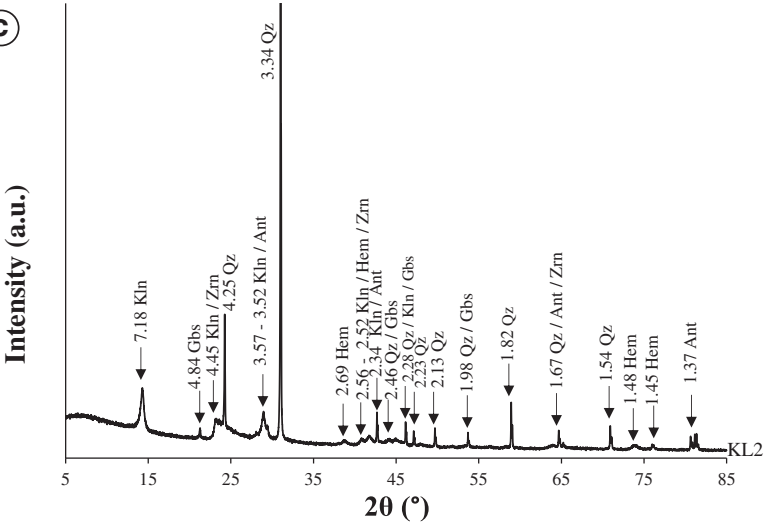

(d)

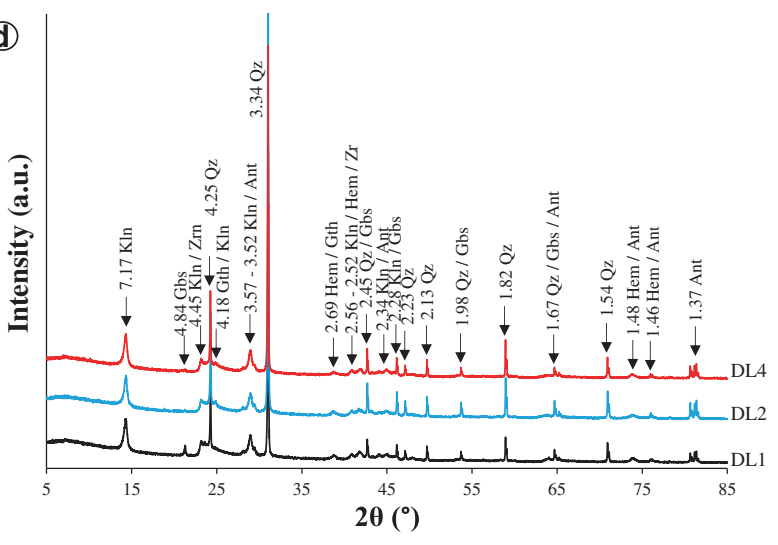

Fig. 4 X-ray diffraction spectra of (a) Koba gleysols, (b) Dimako gleysols, and (c) Koba and Dimako ferralsols 
a

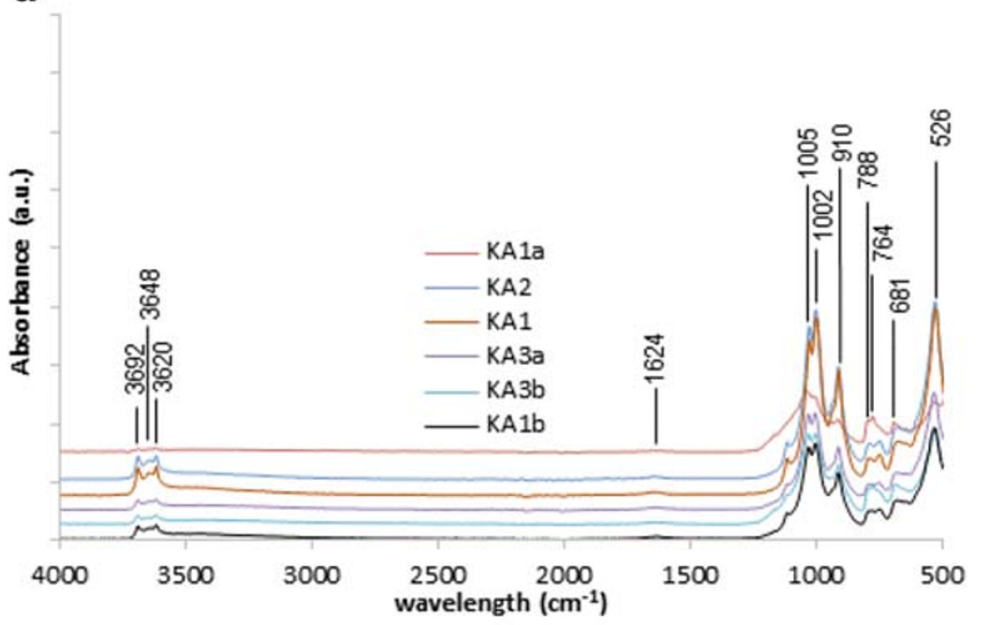

c

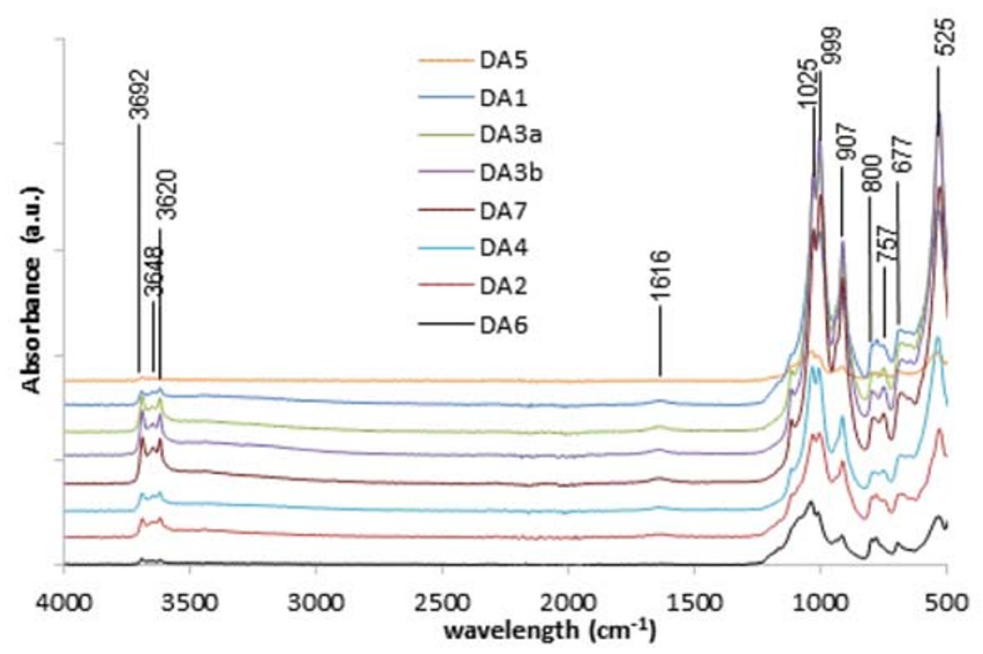

b

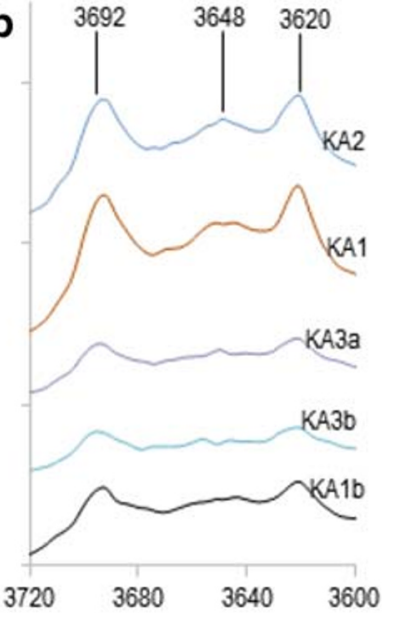

d

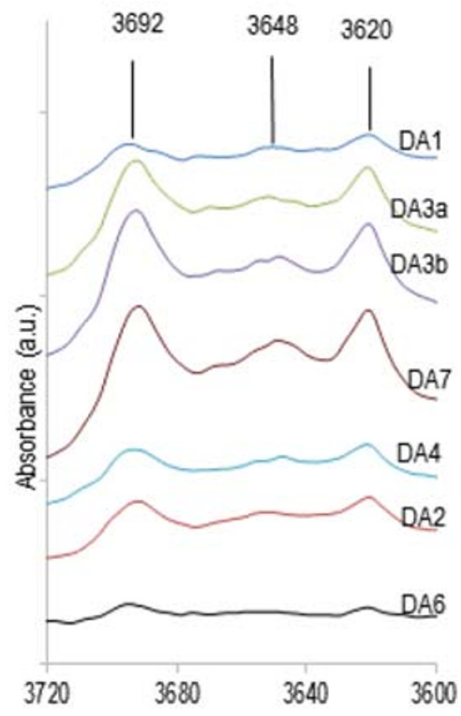

f

e
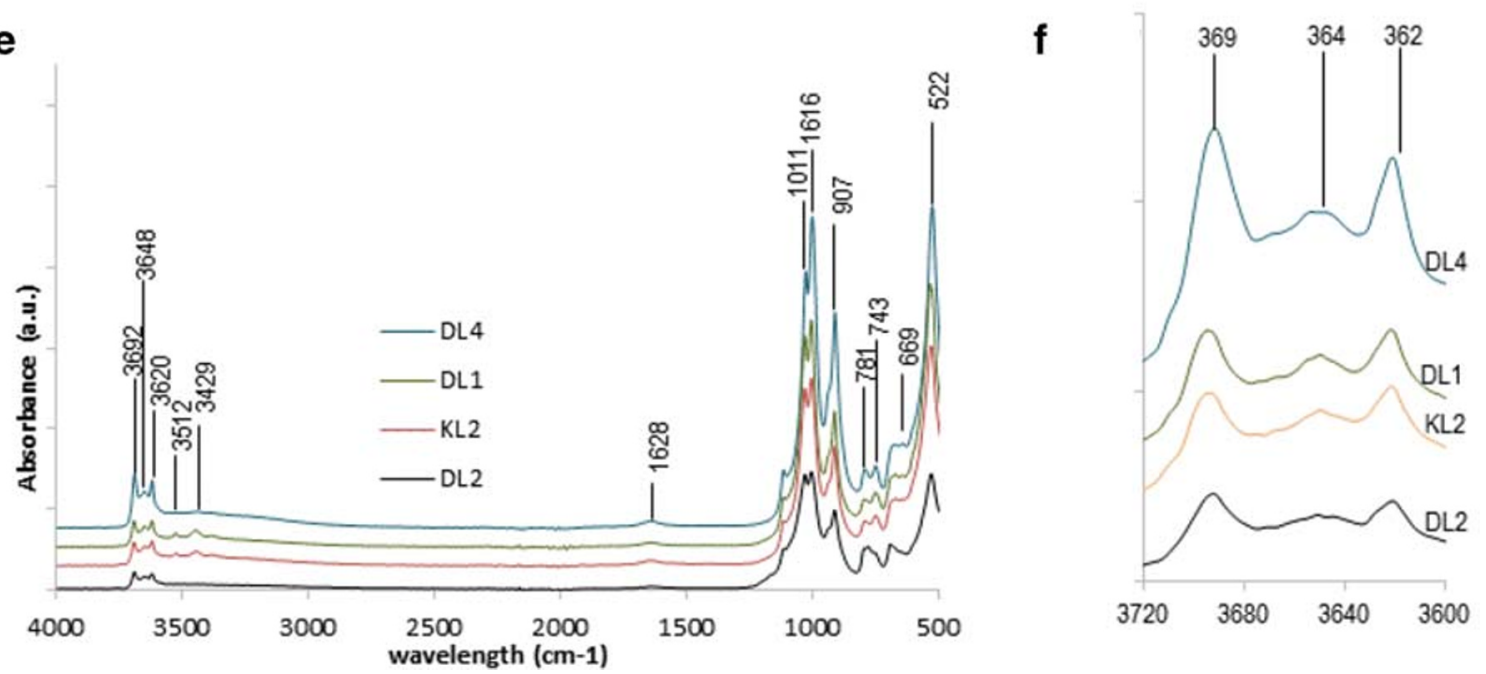

Fig. 5 FT-IR spectra of gleysols and ferralsols between 500 and $4000 \mathrm{~cm}-1$ (a-c-e). b-d-f Diffuse reflectance IR spectra in the $3600-3720 \mathrm{~cm}-1$ region (KA, Koba gleysols; DA, Dimako gleysols; KL, Koba ferralsols; DL, Dimako ferralsols) 
Fig. 6 Binary plots silica vs. selected major elements
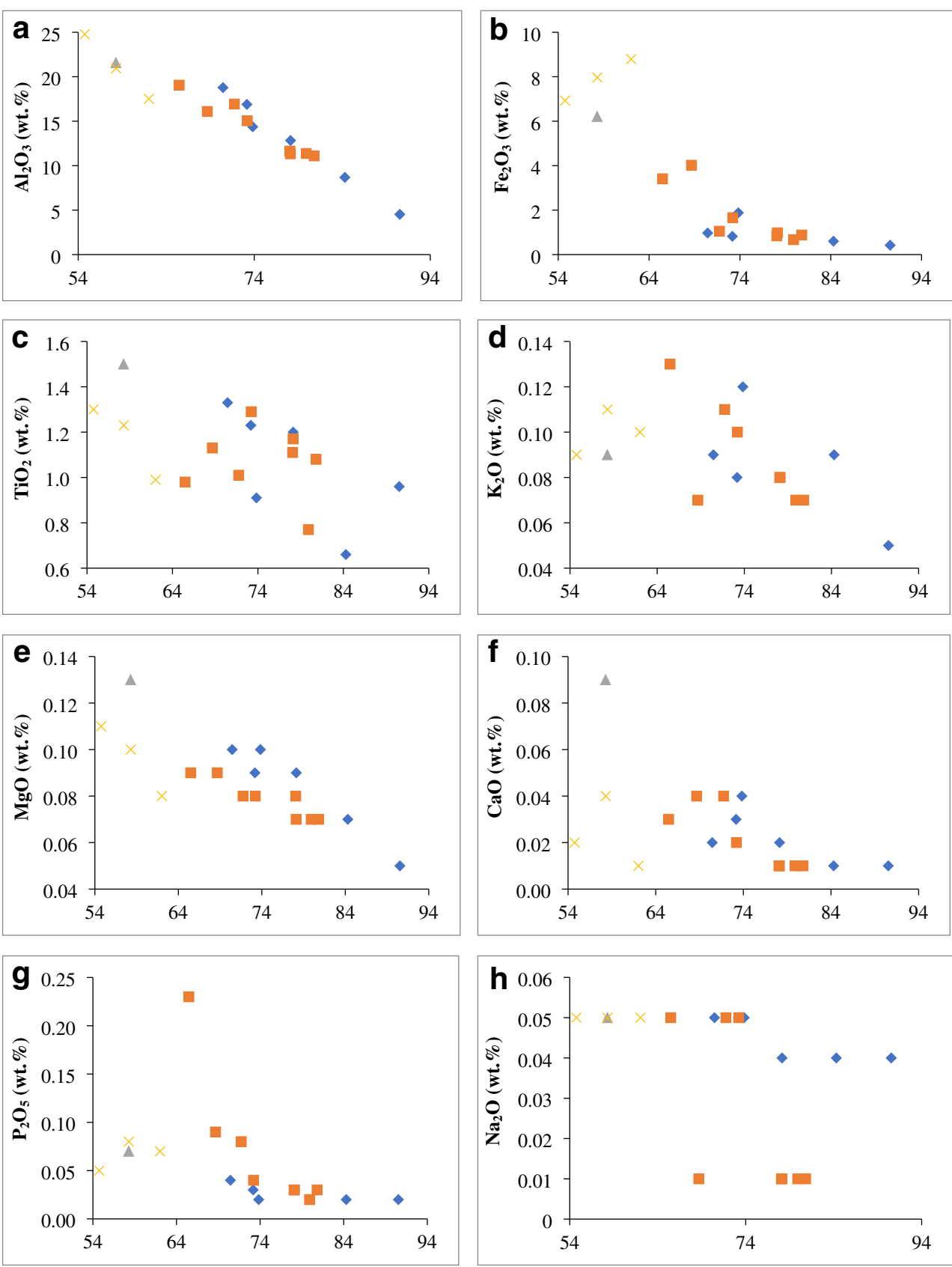

$\mathrm{SiO}_{2}($ wt.\%)

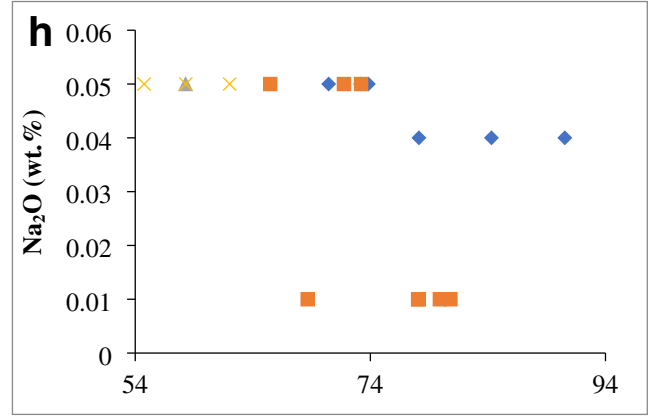

$\mathrm{SiO}_{2}($ wt.\%)

- Koba gleysols = Dimako gleysols Koba ferralsols $\times$ Dimako ferralsols 
Fig. 7 Binary plots of silica vs. selected trace elements
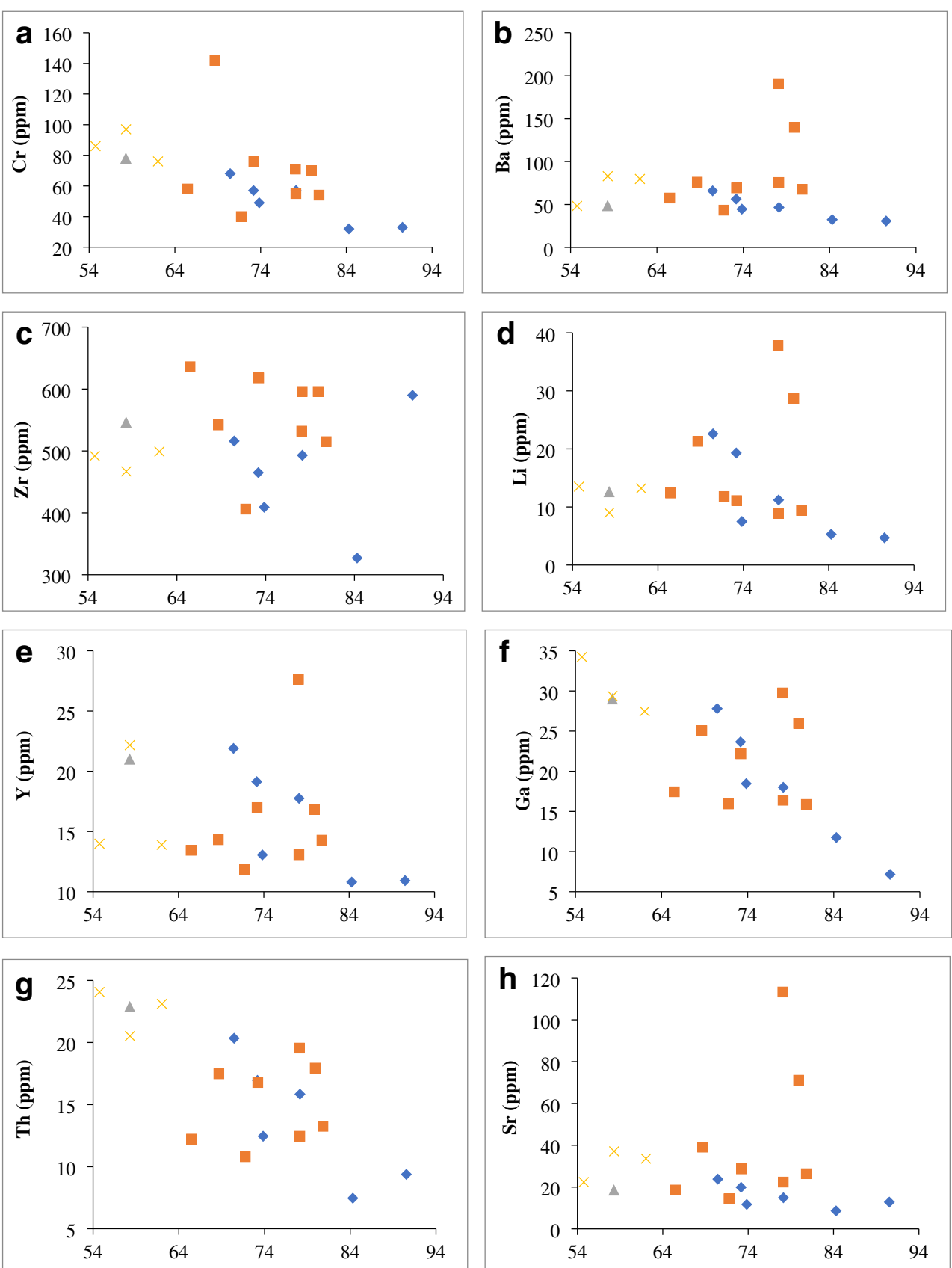

$\mathrm{SiO}_{2}$ (wt.\%)

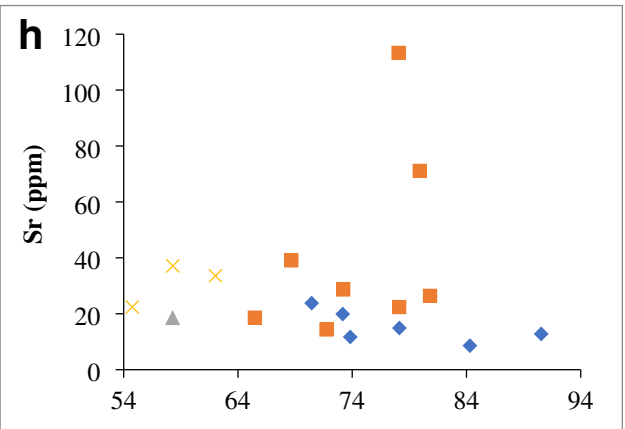

$\mathrm{SiO}_{2}$ (wt.\%)

* Kobagleysols $=$ Dimako gleysols Koba ferralsols $\times$ Dimako ferralsols 

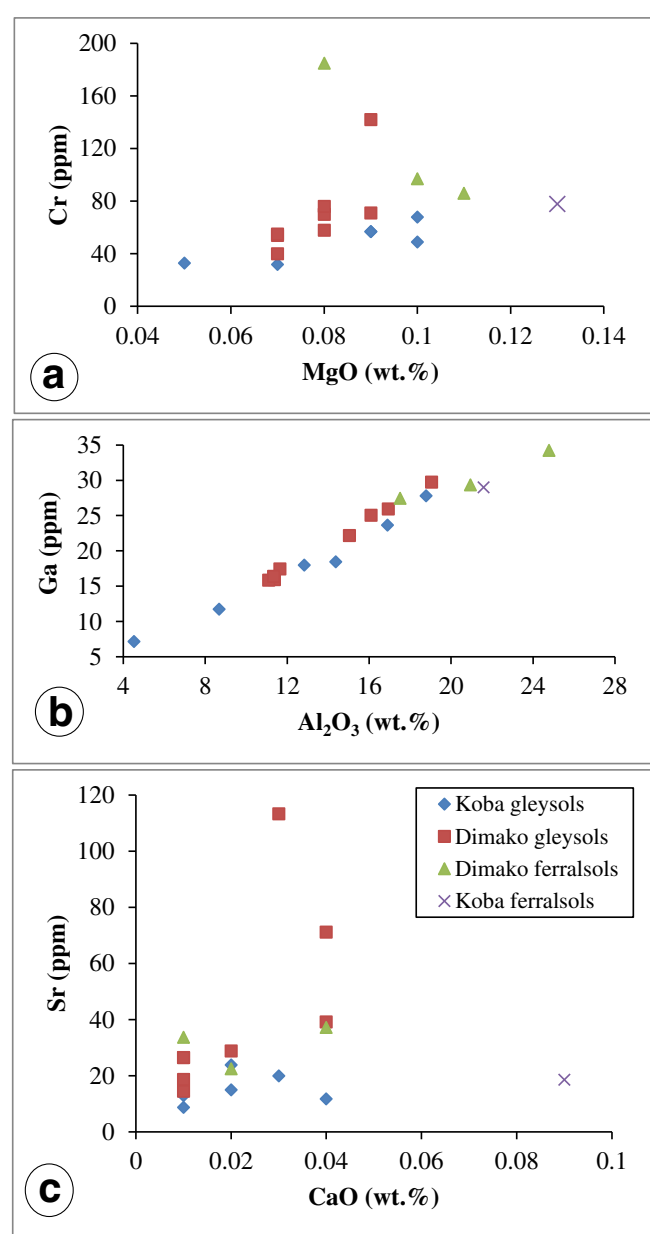

Fig. 8 Binary diagrams of some major elements vs. some trace elements. a $\mathrm{MgO}$ vs. Cr. b $\mathrm{Al} 2 \mathrm{O} 3$ vs. Ga. c $\mathrm{CaO}$ vs. $\mathrm{Sr}$ 
Fig. 9 Primitive mantlenormalized (Sun and McDonough 1989) spider diagrams of trace elements for gleysols (a) and ferralsols (b)
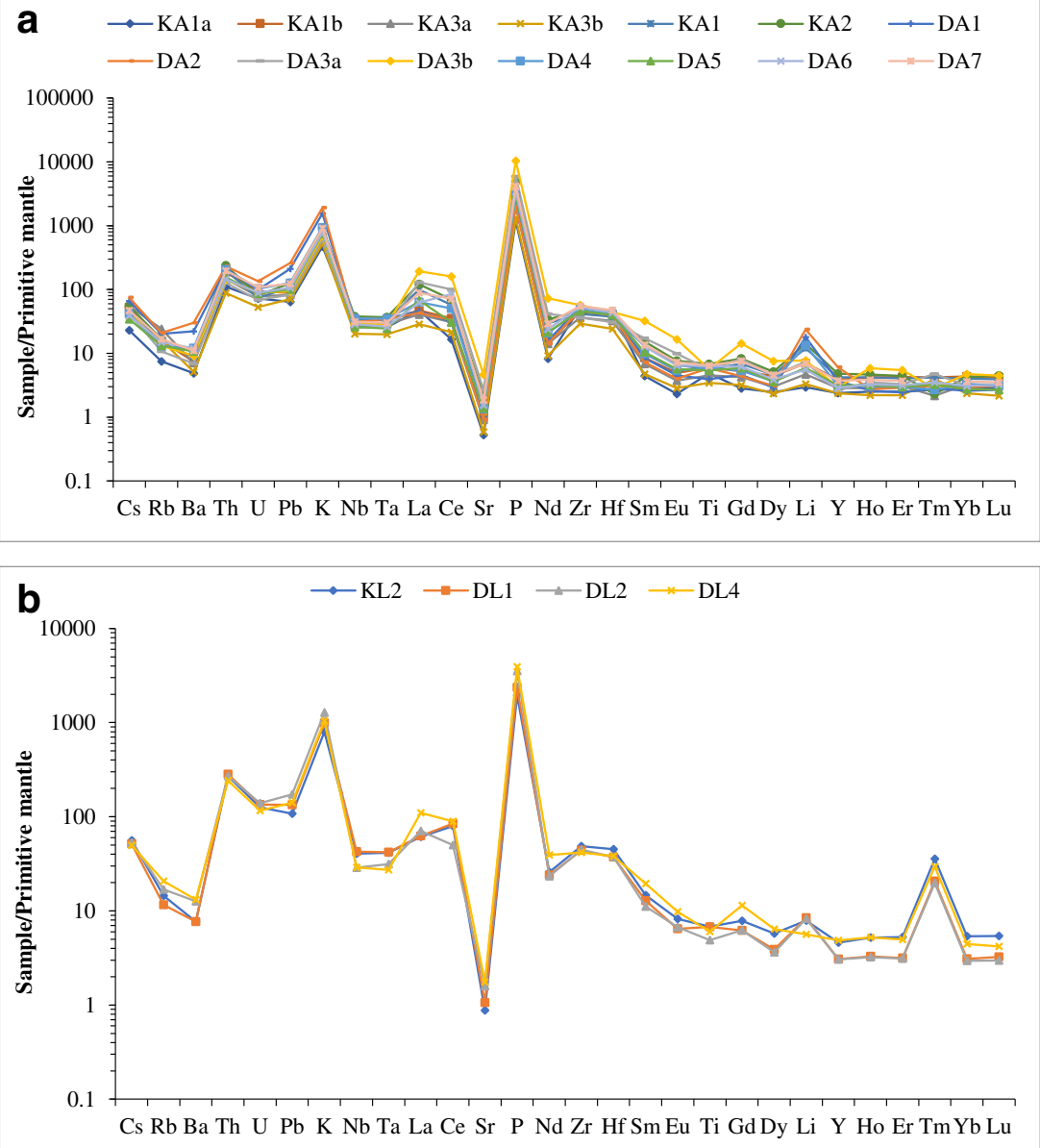
Fig. 10 Rare-earth element patterns of gleysols and ferralsols. a Gneissnormalized. b Granitenormalized. c REE gneiss normalized spectra of ferralsols. REE chondrite normalized patterns of gleysols. d Koba site. e Dimako site. f ferralsols from Dimako (data normalization from McDonough and Sun 1995)
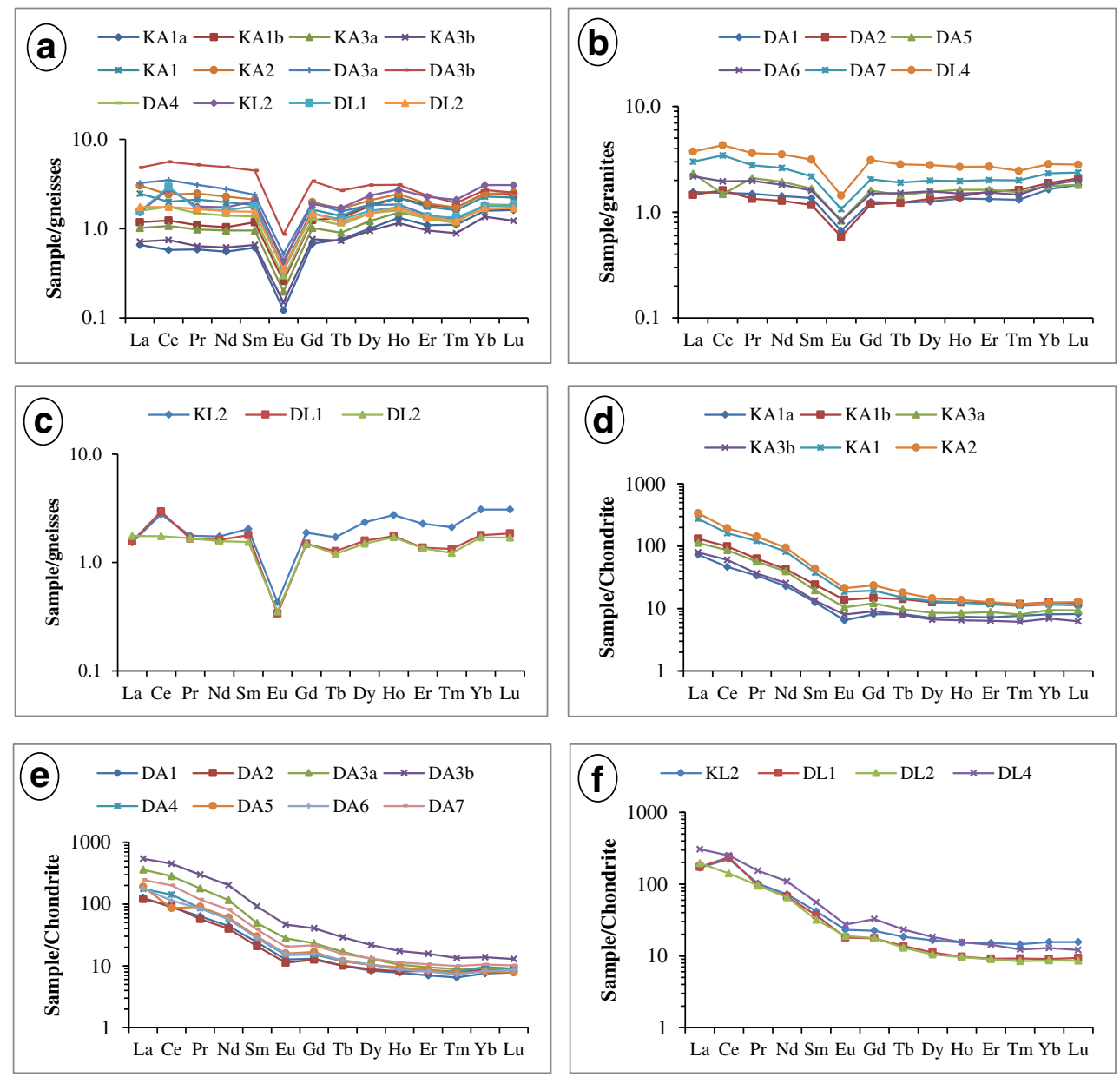
a

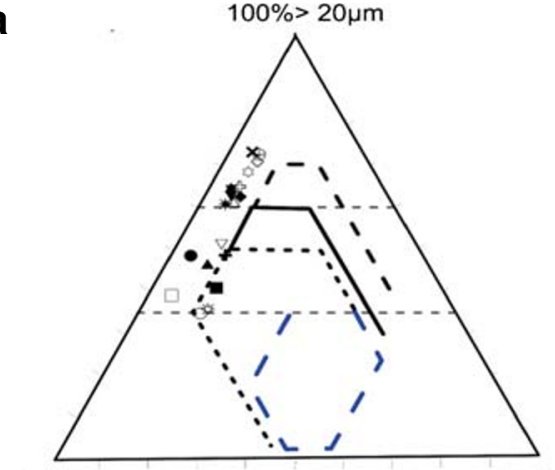

$100 \%<2 \mu \mathrm{m}$

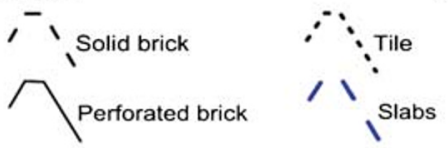

C

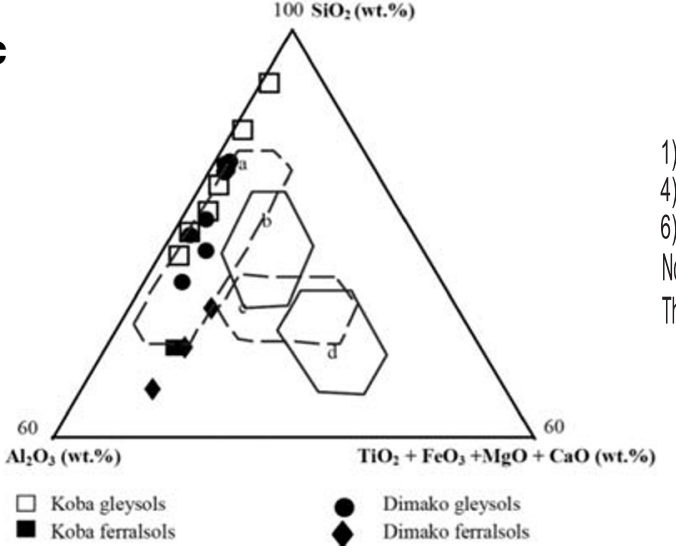

b

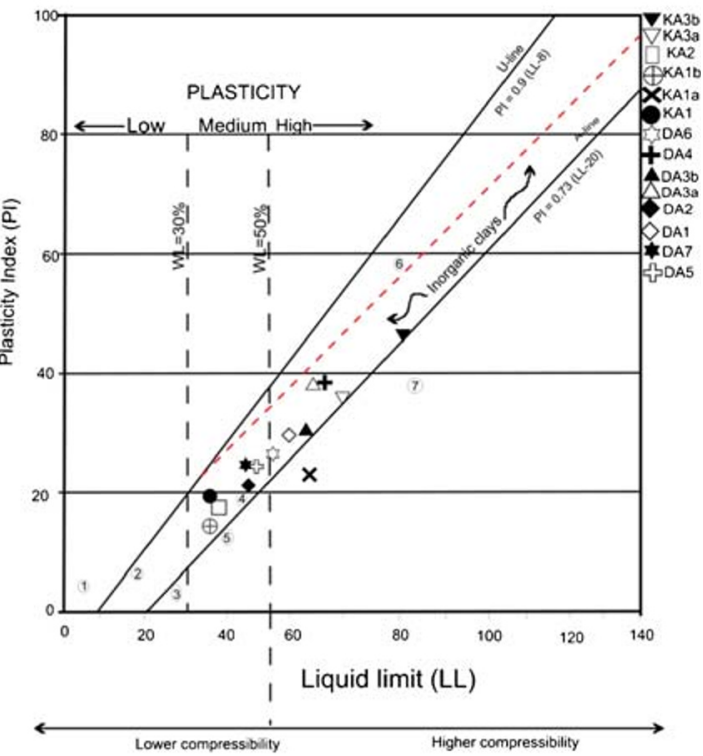

) Cohesion less soils; 2) Inorganic clays, low plasticity; 3) Inorganic silts, low compressibility; 4) Inorganic clays, medium plasticity ; 5) Inorganic silts and organic clays, medium plasticity; 6) Inorganic clays, high plasticity ; 7) Inorganic silt and organic clays, high compressibility Note: The A-line separates the more clay like materials from silty materials, and the organics from the inorganics. The U-ine indicates the upper bound for general soll.

Fig. 11 Empirical diagrams. 1) Winkler and Niesper; 2) Position of gleysols and ferralsols in the Casagrande plasticity chart; 3) Defining suitable domains for types of tiles. a White stoneware tiles. b Red stoneware tiles. c and d Porous tiles (adapted from Fabbri and Fiori 1985) 
Fig. 12 Physicochemical properties of Dimako fired

products. a-b Linear shrinkage

(\%). c-dWater absorption. $\mathrm{e}-\mathrm{f}$

Flexural strength (MPa)
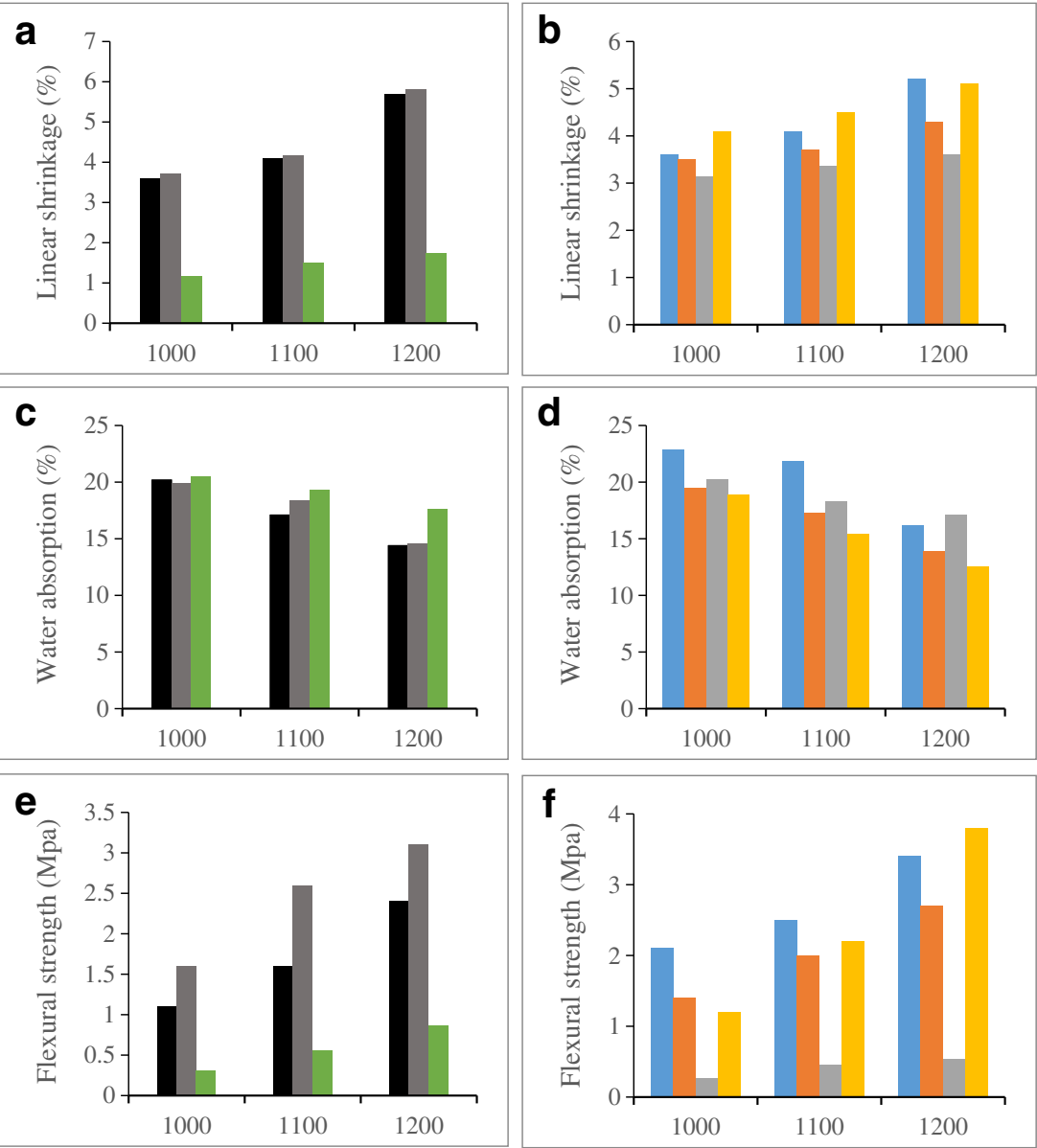

Temperature $\left({ }^{\circ} \mathrm{C}\right)$

- KA1a $=$ KA1

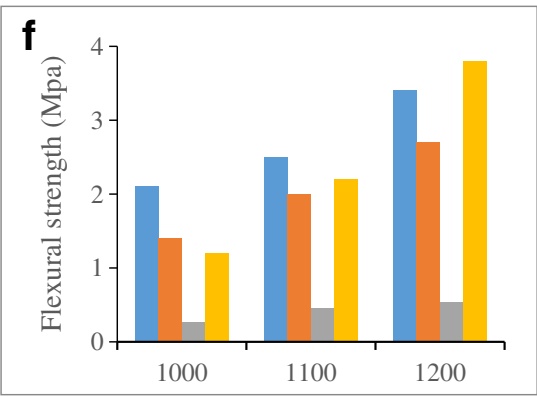

Temperature $\left({ }^{\circ} \mathrm{C}\right)$

$\pm D A 1=D A 3=D A 4=D A 6$ 